\title{
Cercarial Chaetotaxy and Sex Differentiation of Schistosoma mansoni Deriving from Humans and Nectomys squamipes (Muridae: Sigmondontinae) in Brazil
}

\author{
Nilcéa Freire, José Roberto Machado-Silva/ ${ }^{+}$, Rosângela Rodrigues-Silva*, Luís Rey**/ ${ }^{++}$ \\ Departamento de Patologia e Laboratórios, Faculdade de Ciências Médicas, Universidade do Estado do Rio de Janeiro, Av. 28 de \\ Setembro 87 fundos, $5^{\circ}$ andar, 20551-001 Rio de Janeiro, RJ, Brasil *Laboratório de Helmintos Parasitos de Vertebrados, \\ Departamento de Helmintologia **Laboratório de Biologia e Controle da Esquistossomíase, Departamento de Medicina Tropical, \\ Instituto Oswaldo Cruz-Fiocruz, Rio de Janeiro, RJ, Brasil
}

A comparative study was made between sympatric isolates of Schistosoma mansoni: one from a wild rodent $(R)$ Nectomys squamipes and another one from humans $(H)$ isolated from a low endemic schistosomiasis transmission area in Brazil. Our purpose was to detect differences between them concerning chaetotaxy (number and pattern of distribution of the argentophilic papillae) of the cercariae by means of silver impregnation. No significant difference $(x>0.05)$ between isolates was noted. Nevertheless, a significant difference $(x<0.05)$ was observed in the cercarial index (ratio of the distance between the first and the second preacetabular papillae and the distance between the first and the second dorsal preacetabular papillae) of male and female cercariae in both isolates. Males presented a greater cercarial index than females. By means of multivariate analysis, male cercariae were distinguished from female cercariae through the following characteristics: average number of dorsal papillae on the right quadrant, average number of ventral middle papillae on the right quadrant ( $H$ isolate) and average number of dorsal middle papillae on the left quadrant ( $R$ isolate). The results suggest that $R$ and $H$ isolates belong to the same population that could complete its life cycle in rodent-snail-rodent fashion.

Key words: Schistosoma mansoni - cercariae chaetotaxy - sex determination - Nectomys squamipes - human host schistosomiasis mansoni - Brazil

In some areas of schistosomiasis mansoni transmission in Africa and in the Antilles, certain rodent $(\mathrm{R})$ species behave as hosts for Schistosoma mansoni (Combes et al. 1976, Rodrigues e Silva et al. 1992). In Guadeloupe three types of foci were identified: transmission exclusively between humans $(\mathrm{H})$, between $\mathrm{H}$ and $\mathrm{R}$ (amphixenosis) and exclusively between R (Cassone et al. 1981). In Brazil some R species with semi-aquatic habits, with different degrees of sinantropic, are considered as possible reservoirs for S. mansoni (Rey 1993). To date, no transmission area exclusive to $\mathrm{R}$ has been identified, however, the infection level of these hosts increases with proximity to $\mathrm{H}$ housing (D'Andrea et al. 2000). Nonetheless, little is known about the phenotypic characteristics of the larvae forms (cercariae) of the strains of parasites isolated from these hosts.

Chaetotaxic study has allowed the characterization of interspecific variations of $S$. mansoni. African strains present lateral papillae in a triangular shape and a cercarial index of 1.0. They are thus different from American strains where the disposition is linear and the index is greater (1.01.4) (Bayssade-Dufour 1979b). Between two strains (JR e C5) from Venezuela, it has been demonstrated that the former demonstrated a higher variation coefficient in the total number of papillae (dorsal and ventral) and more than one anterior ventral papilla (Pino et al. 1997). Variations have also been detected between the cercarial indices of $\mathrm{H}$

\footnotetext{
${ }^{+}$Corresponding author and CNPq and Faperj fellow. Fax: + 5521-2587.6112.E-mail: machado @uerj.br

${ }^{++} \mathrm{CNPq}$ fellow

Received 3 May 2001

Accepted 28 August 2001
}

(1.0-1.4) and murine (1.34-2.0) strains, in the S. mansoni foci in Guadeloupe (Bayssade-Dufour 1977, Cassone et al. 1981).

Among the strains that exist in Brazil, it is known that LE, SJ and another one from Recife (kept for several generations under laboratory conditions) present significant differences in the cercarial index (Cassone et al. 1978, Araújo et al. 1987). However, there are no comparative chaetotaxic studies of cercariae from $\mathrm{H}$ and $\mathrm{R}$ isolates.

This article adds to a comparasion between the morphological characteristics (Machado-Silva et al. 1994, Neves et al. 1998) of sympatric isolates, derived from a low level endemic area (Rey 1993), where schistosomiasis infection is present in the H population and in the wild $\mathrm{R}$ Nectomys squamipes (Rodrigues e Silva et al. 1992, D'Andrea et al. 2000).

\section{MATERIALS AND METHODS}

Isolates studied - The sympatric parasites studied in this trial were obtained from the Pamparrão Valley, a rural area in the municipality of Sumidouro ( $22^{\circ} 02^{\prime} 46^{\prime \prime} \mathrm{S}$; $42^{\circ} 41^{\prime 2} 1^{\prime \prime} \mathrm{W}$ ), about $200 \mathrm{~km}$ from Rio de Janeiro City, State of the Rio de Janeiro, Brazil. The isolates were studied in their first passage under laboratory conditions.

The $\mathrm{H}$ isolate was obtained from the stools of autochthonous subjects and the $\mathrm{R}$ isolate from liver, stools or bowel contents of 13 specimens of $N$. squamipes $(2 \mathrm{n}=56)$ (Bonvicino et al. 1996). The isolation methodology and the maintenance in the laboratory have been presented in another publication (Machado-Silva et al. 1994). Specimens from a sympatric Biomphalaria glabrata colony, kept under laboratory conditions, were exposed to unimiracidial infection of $\mathrm{R}$ or $\mathrm{H}$ isolates. The snails were kept in glass aquariums and fed with fresh lettuce (Lacttuca sativa).

The cercariae eliminated after exposure of snails to a light source, were stained with silver nitrate, placed on a 
glass slide (Combes et al. 1976) and drawn in a light chamber (Olympus model BH2-DA). A lens with amplification 40, a WHK 10X ocular and a NFK 5xLD photographic ocular was used. A lens with 100 magnification with the same ocular and photographic ocular was used in order to determine the cercarial index.

Calculation of the cercarial index - Defined as the ratio of the distance between the first and the second preacetabular papillae and the distance between the first and the second dorsal preacetabular papillae (Fig. 1A, B) according to Bayssade-Dufour (1979a): $\mathrm{n}=1 / 2\left(\mathrm{x}_{1} / \mathrm{y}_{1}+\mathrm{x}_{2} /\right.$ $\left.\mathrm{y}_{2}\right)$, were $\mathrm{x}_{1}$ and $\mathrm{x}_{2}$ : distances between the first AIL papilla and the AIIL papilla, for each of the cercarial hemi-bodies; and $\mathrm{y}_{1}$ and $\mathrm{y}_{2}$ : distance between the AID papilla and AIID papilla, of each cercarial hemi-body.

A lens with 100 magnification was used to determine the cercarial index, with the same oculars and photographic ocular as mentioned above. The distances (in $\mu \mathrm{m}$ ) were determined for 120 cercariae in each isolate.

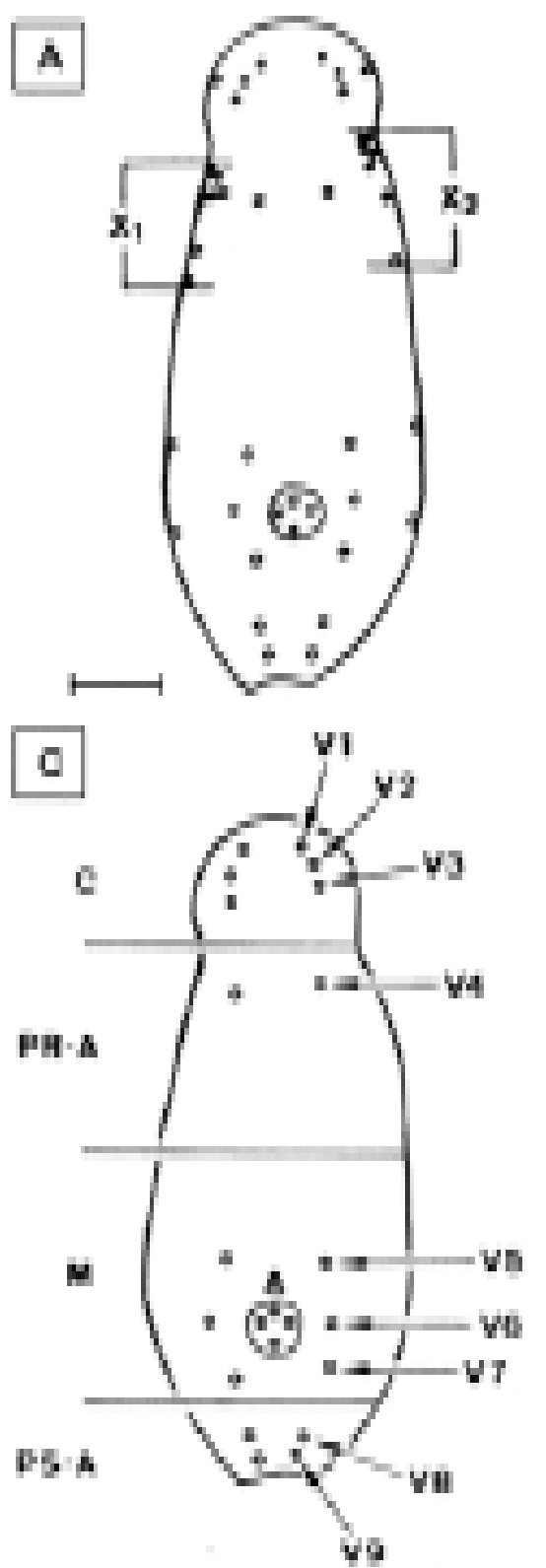

Determination of the number of dorsal and ventral papillae - The papillae on the dorsal and ventral faces of the cercarial body were counted and the papillae on the right and left hemi-bodies of the two faces were quantified.

Spatial disposition of papillae - We used a combination of the methodologies as proposed by Richard (1971) and Short and Cartrett (1973) with slight modifications. The cercarial body was divided in four parts: cephalic, preacetabular, medial e post-acetabular. The papillae were numbered starting from the first cephalic papilla (Fig. 1C, D). The displacement or absence of papillae were recorded as was the presence of supernumerary papillae, according to the number and position in one of the segments of the cercarial body, on the right and left hemi-bodies of the dorsal and ventral faces. For each isolate, at least 30 cercariae were drawn.

Sex determination of cercariae - Mus musculus Swiss Webster supplied by the Center for Laboratory Animal
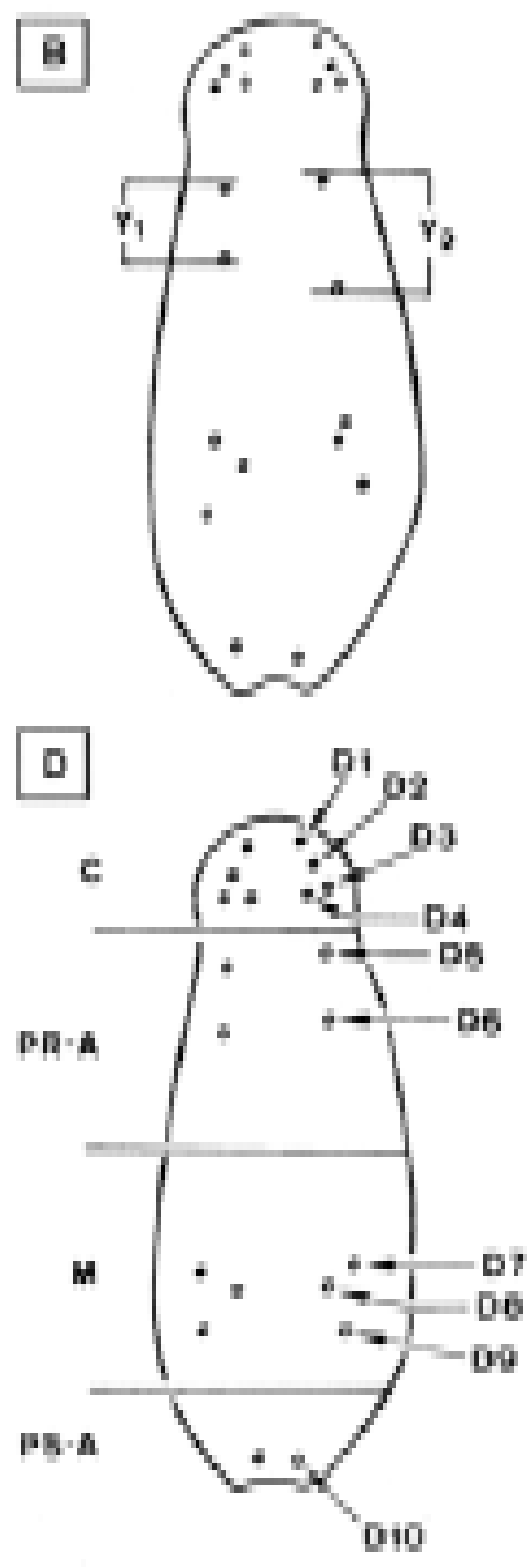

Fig. 1: location and nomenclature of the cercariae papillae from human and murine isolates from the municipality of Sumidouro, State of Rio de Janeiro, Brazil. A, C: ventral face; B, D: dorsal face; C: cephalic segment; PR-A: pre-acetabular segment; M: medial segment; PSA: post-acetabular segment; A: acetabular; Bar $=0.08 \mathrm{~mm}$ 
Breeding at the Oswaldo Cruz Institute-Fiocruz, Brazil, were exposed to 50 cercariae each shed by B. glabrata from the $\mathrm{H}$ or R isolates. Six animals were used for each isolate. After six weeks, the animals were killed and perfused (Smithers \& Terry 1965) while the worms were identified according to their sex. The animals were fed processed fodder for mice and rats (NUVILAB ${ }^{\circledR}$ ) ad libiditum, as well as water. The sacrifice of the animals followed the standards in force regarding ethical procedures for laboratory animals (GV-SOLAS 1985).

Statistical analysis - Student's t test was used for determination of mean differences of the chaetotaxic values and the multivariate discriminating analysis (Morrison 1967) to distinguish the observations on cercarial sex. Eleven variables were used (Table I). The significance level adopted was $5 \%$. The data processing was carried out using BMDP-7M software.

\section{TABLE I}

Variables employed in the analyses of cercariae of human $(\mathrm{H})$ and rodent $(\mathrm{R})$ isolates in the municipality of Sumidouro, State of Rio de Janeiro, Brazil

\begin{tabular}{cccccc}
\hline \multirow{2}{*}{$\begin{array}{c}\text { Character } \\
\text { number }\end{array}$} & \multicolumn{2}{c}{$\mathrm{H}$} & & \multicolumn{2}{c}{$\mathrm{R}$} \\
\cline { 2 - 3 } \cline { 5 - 6 } & Males & Females & & Males & Females \\
\hline 1 & $36.73 \pm 1.38$ & $38.33 \pm 1.44$ & & - & - \\
2 & $16.93 \pm 1.05$ & $18.00 \pm 0.94$ & & - & - \\
3 & $19.80 \pm 0.61$ & $20.33 \pm 1.06$ & & - \\
4 & $8.50 \pm 0.63$ & $9.00 \pm 0.58$ & & - \\
5 & $8.43 \pm 0.68$ & $9.00 \pm 0.52$ & $17.00 \pm 1.05$ & $17.60 \pm 1.00$ \\
6 & $9.86 \pm 0.34$ & $10.23 \pm 0.62$ & - & - \\
7 & $2.43 \pm 0.50$ & $2.96 \pm 0.31$ & - & - \\
8 & - & - & $8.40 \pm 0.72$ & $8.83 \pm 0.59$ \\
9 & $2.56 \pm 0.56$ & $2.86 \pm 0.50$ & - & - \\
10 & $1.90 \pm 0.40$ & $2.06 \pm 0.36$ & - & - \\
11 & - & - & $1.80 \pm 0.48$ & $2.06 \pm 0.25$ \\
\hline
\end{tabular}

-: not observed

\section{RESULTS}

Cercarial index - For the male cercariae from the $\mathrm{H}$ isolate the cercarial index was $1.6 \pm 0.8 \mu \mathrm{m}$ and for the $\mathrm{R}$ isolate $1.3 \pm 0.3 \mu \mathrm{m}$. Among the females, the indices from the $\mathrm{R}$ isolate $(1.4 \pm 0.3 \mu \mathrm{m})$ were greater than for the $\mathrm{H}$ isolate $(1.2 \pm 0.3 \mu \mathrm{m})$. According to Student's t test, the values obtained for males and females in both isolates were considered significant at the $5 \%$ level. When a comparison between the indices presented by males and females of each isolate were made, the difference was also significant at the 5\% level.

Total number of dorsal and ventral papillae - This varied from 38 to 46 . Both isolates presented a greater variation on the dorsal face (18-25) than on the ventral face (17-23).

Spatial disposition of papillae - In both isolates a marked variability was observed on the ventral face of the cercariae. On this face there was a marked constancy of papillae located on the cephalic segment (V1, V2 and V3) and the preacetabular (V4) of the cercarial body. The highest number of displacements (Fig. 2A, C, F), papillary absences (Fig. 2B, D, E) or supernumerary papillae (Fig. 2F) occurred on the medial (V5, V6 and V7) and the postacetabular (V9 and V10) segments. The lack of V7 papilla was observed in both hemi-bodies (Fig. 2D, E).
On the dorsal face, the greatest variability occurred on the medial segment (papillae D7, D8 and D9). The cephalic segment papillae (D1, D2, D3 and D4) and the preacetabular segment (D5 and D6) were very constant. No variations in the acetabular papillae were observed with the exception of a duplication of D5 on the left hemi-body (Fig. 3C). On this dorsal face there was also a lack of papillae (Fig. 3A, C) and supernumerary papillae (Fig. 3B, D).

All observations are valid for both isolates. In relation to the sex of the cercariae, the greatest variability in the chaetotaxic standard occurred in the males of both isolates.

None of the variables analyzed were able to distinguish the isolates. In constrast, significant differences (at the $5 \%$ level) between the sexes of the cercariae were observed. For isolate $\mathrm{H}$, there were nine variables and for isolate R three variables (Table II). According to the Jackknifed classification, the variables that presented the highest discriminatory power between the sexes were different for each isolate: the number of papillae on the dorsal face of the right hemi-body (number 6), the number of medial papillae on the ventral face of the right hemi-body (number 7) (isolate $\mathrm{H}$ ) and the number of medial papillae on the dorsal face of the left hemi-body (number 11) (isolate R).

\section{DISCUSSION}

Given that digenetic trematodes are primitively snail parasites and not parasites of vertebrates (Richard 1971), it is convenient to refer to the cercariae to base one's classification. The chaetotaxic study of cercariae has been used as a tool to characterize strains of $S$. mansoni, particularly where there are H and R strains (Bayssade-Dufour 1979b, Cassone et al. 1981). However, in this trial with sympatric populations, a characteristic cercarial index for each isolate was not observed, which points to the absence of genetic variability between them. This observation is consistent with the results obtained with sympatric isolates of $\mathrm{H}$ or murine origin from Senegal, where the analysis of isoenzymes was used (Sène et al. 1997). It has been demonstrated, through the use of DNA analysis, that strains that are geographically close present homology (Pillay \& Pillay 1994, Pinto et al. 1997). Even the strains that are geographically different present over $90 \%$ similarity (Pillay \& Pillay 1994).

On the other hand, our data contrast with observations that determined specific indices for strains from Africa and the Antilles with different vertebrate hosts (nonhuman primate and rodent) (Bayssade-Dufour 1977). This divergence is also present in the findings made with cercariae shed by naturally infected snails and among $\mathrm{H}$ and $\mathrm{R}$ strains from Guadeloupe (Cassone et al. 1981). In this case, indices around 1.30 could indicate the existence of strains that moved alternately between $\mathrm{H}$ and R (BayssadeDufour 1979b). In our opinion, this index, as well as other behavioral characteristics, present a variation within certain limits. Therefore, what characterizes a certain isolate is the frequency with which these values occur. The vertebrate hosts influence this variability by selecting certain patterns. In this way, the cercarial index may vary in the same location or in different locations, according to the participation of each possible vertebrate host in the epidemiological chain of schistosomiasis mansoni. In addition, this host can present subpopulations of worms with different genotypes, as was shown in the $R$. rattus from Guadeloupe (Barral et al. 1996). 
In our trial, no specific cercarial index was observed for the different isolates. This constrast with demonstrations made with other Brazilian strains (LE and SJ) (Araújo et al. 1987), which are allopatric and have been kept for more than 30 years under laboratory conditions. This condition is recognized as one of the factors that can lead to the selection of a strain's chaetotaxic pattern (Cassone et al. 1978). It must be noted that the isolates that were used in our trial were in their first passage through laboratory conditions. It has been demonstrated that isolates recently introduced to the laboratory present a greater genomic variability than those kept for more generations (Vieira et al. 1991, Pinto et al. 1997).

With regard to the number and spatial distribution of the body papillae, we observed that certain papillary clusters are more constant than others and that the dorsal face is more stable than the ventral one. These results confirm previous information regarding the existence of more or less stable papillary clusters (Richard 1971, BayssadeDufour 1979a). We observed a marked absence of the 7 th ventral papilla (medial segment) in the Sumidouro isolates. This fact was not recorded for any cercariae papillae of a Puerto Rican strain (Short \& Cartrett 1973).

The results of the present trial demonstrate that the
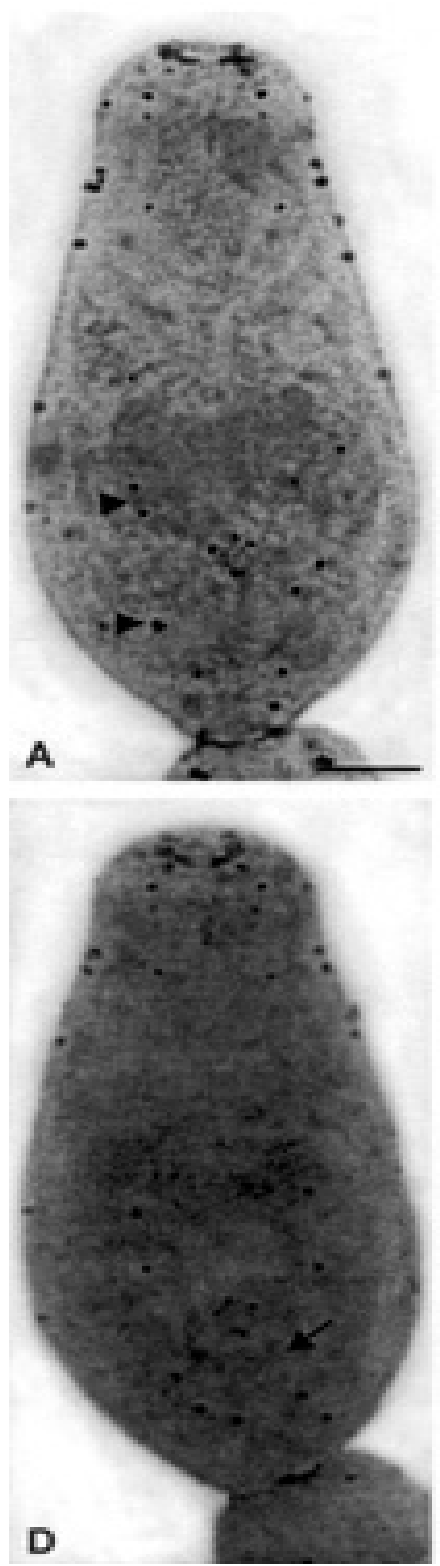
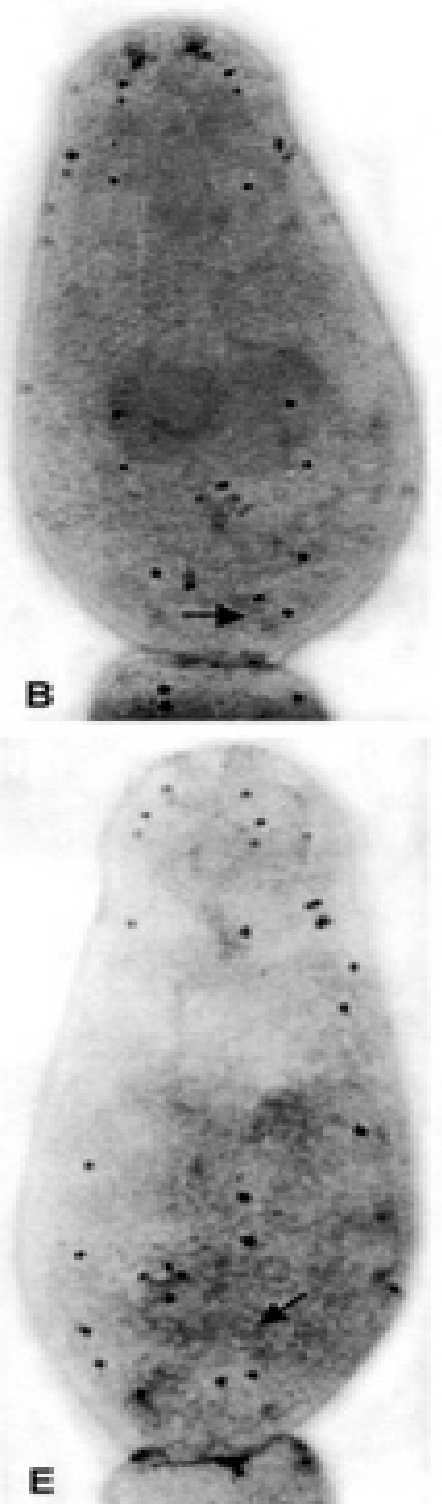

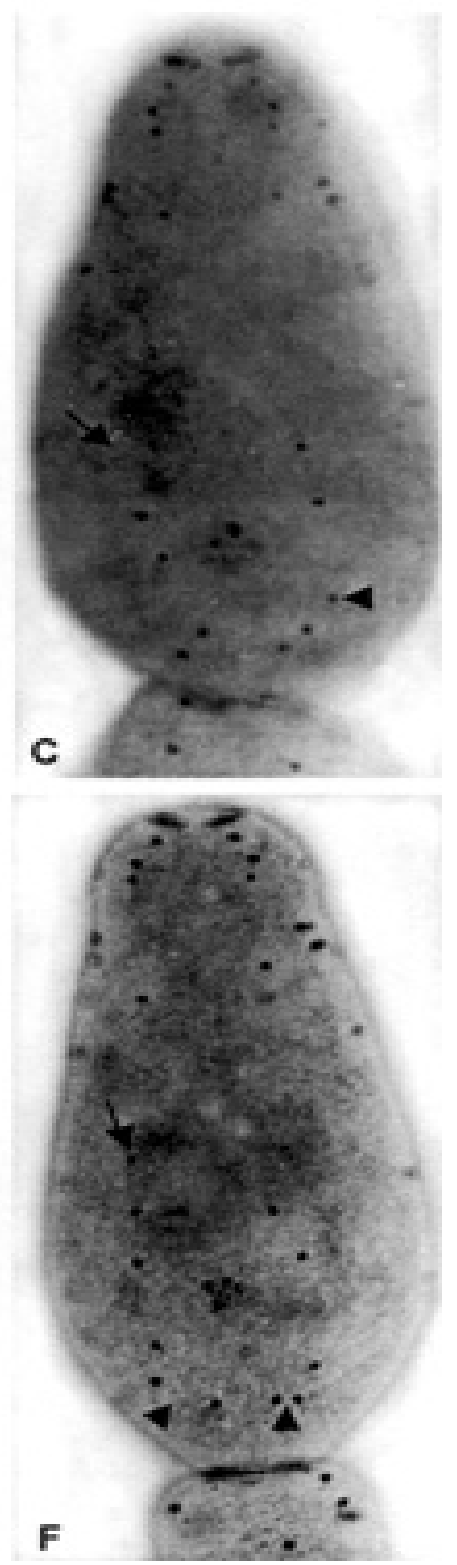

Fig. 2: variation in the spatial distribution of ventral body papillae in cercariae of human and rodent isolates from the municipality of Sumidouro, State of Rio de Janeiro, Brazil. A: displacement of medial and postacetabular papillae of right hemi-body ( $\mathbf{})$; B: absence of 9th postacetabular papilla of right hemi-body $(\rightarrow)$; C: absence of 5th medial papilla of right hemi-body $(\rightarrow)$; displacement of 7 th medial papilla of left hemi-body $(\boldsymbol{\nabla})$; D: absence of 7th medial papilla of left hemi-body $(\rightarrow)$; E: absence of 7th medial papilla of left hemi-body $(\rightarrow)$; F: presence of supernumerary papilla between the 4th and 5th papillae of right hemi-body $\rightarrow$ ); displacement of postacetabular papillae in right and left hemi-bodies $(>)$; Bar $=0.08 \mathrm{~mm}$ 
sex of the cercariae can be distinguished at the phenotypic level though chromosomal analyses also allow sex determination (Quack et al. 1998). Furthermore, differences in the chaetotaxic pattern of male and female cercariae have been confirmed (Pino et al. 1988). Unlike these authors, however we observed that the female cercariae presents greater homogeneity in the total number of papillae of the cercarial body. Discriminant analysis applied to chaetotaxy is a fundamental tool for separating cer-

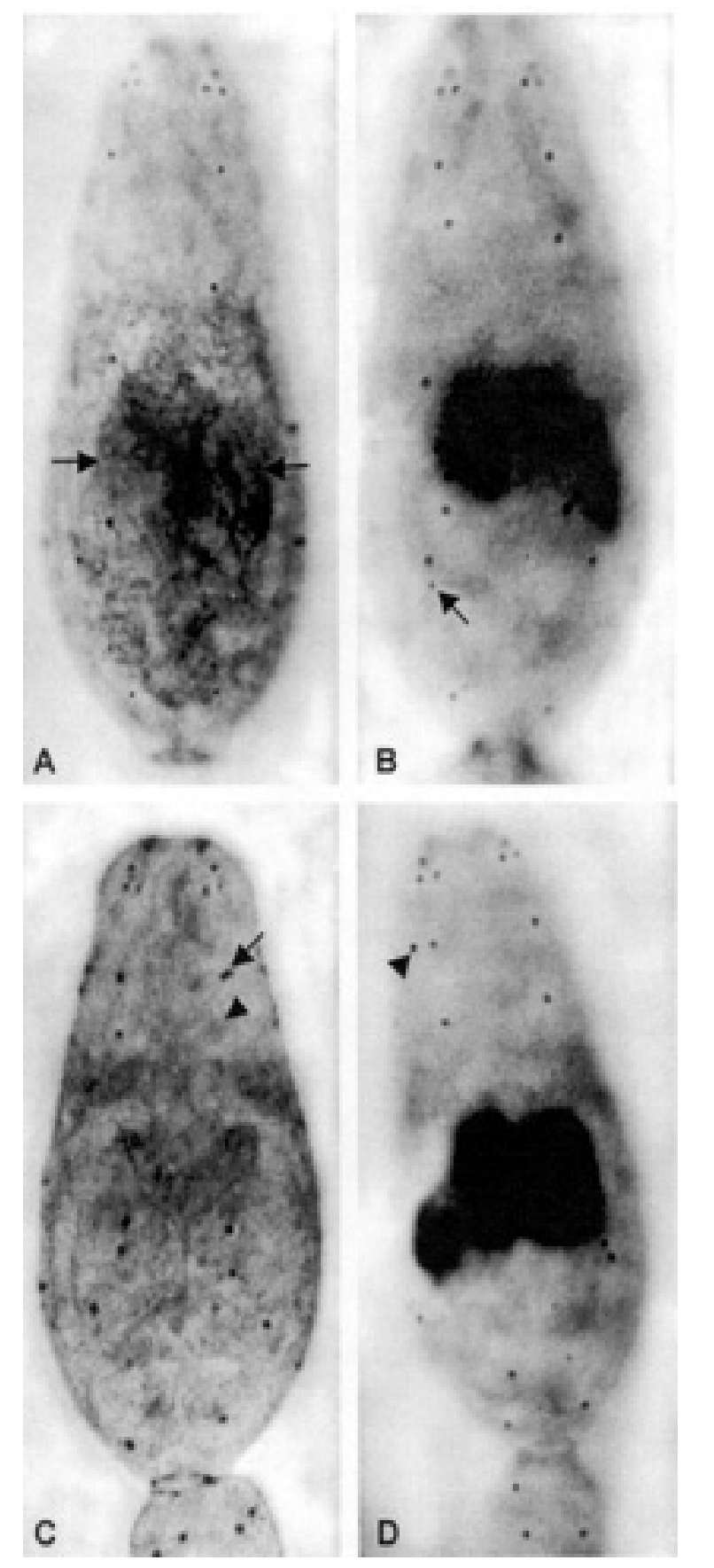

Fig. 3: variation in distribution of dorsal body papillae in cercariae of human and rodent isolates from the municipality of Sumidouro, State of Rio de Janeiro, Brazil. A: absence of 7th medial papilla in right and left hemi-bodies $(\rightarrow)$; B: presence of supernumerary papilla between the 9 th and 10th papillae in the right hemi-body $(\rightarrow)$; C: duplication of 5th pre-acetabular papilla in left hemi-body $(\rightarrow)$; absence of 6 th pre-acetabular papilla in left hemi-body ( ); D: presence of supernumerary papilla at the 5 th pre-acetabular papilla level $(\downarrow)$; Bar $=0.08 \mathrm{~mm}$

\section{TABLE II}

Biometric measurements (mean and standard deviation) of the taxonomic characters in Schistosoma mansoni male and female cercariae deriving from human $(\mathrm{H})$ or rodent $(\mathrm{R})$ isolates

\begin{tabular}{cl}
\hline Number & Identification \\
\hline 1 & Total number of papillae \\
2 & Number of ventral papillae \\
3 & Number of dorsal papillae \\
4 & Number of papillae on the ventral face \\
5 & Left hemi-body \\
& Number of papillae on the ventral face \\
6 & Right hemi-body \\
7 & Number of papillae on the dorsal face \\
& Right hemi-body \\
8 & Missing papillae on the ventral face \\
9 & $\begin{array}{l}\text { Right hemi-body } \\
9\end{array}$ \\
& Right hem of medial ventral papillae \\
10 & Number of ventral post acetabular papillae \\
11 & Right hemi-body \\
& Number of ventral papillae. Left hemi-body \\
& Number of ventral post acetabular papillae \\
\hline
\end{tabular}

cariae of both sexes. Thus, about $66 \%$ cases were exactly classified according to the total number of papillae (Pino \& Morales, 1990). In this experiment similar data were found. The smallest deviations in cercarial indices, the smaller difference between the male and female indices and the lower number of variables that are able to distinguish the sexes, indicate that the $\mathrm{R}$ isolate is more homogenous than the $\mathrm{H}$ isolate. Morphological studies in adult worms of these same isolates support this opinion (Machado-Silva et al. 1994, Neves et al. 1998). The results suggest that in this focus (Pamparrão Valley, Sumidouro), $\mathrm{R}$ and $\mathrm{H}$ isolates belong to the same population that could complete its life cycle in a rodent-snailrodent fashion.

\section{ACKNOWLEDGEMENTS}

To Genilton José Oliveira and Heloísa Maria Nogueira Diniz, Education Department, Oswaldo Cruz Institute, for their technical support with the photographs. To Roberto Magalhães Pinto, Laboratory of Helminths Parasites of Vertebrates, Helminthology Department, Oswaldo Cruz Institute, for his collaboration with cercariae morphometry.

\section{REFERENCES}

Araújo N, Souza CP, Katz N 1987. Tentativa de diferenciação de linhagens de Schistosoma mansoni utilizando cercárias coradas por nitrato de prata. Rev Soc Bras Med Trop 20: 37.

Barral V, Morand S, Pointier JP, Théron A 1996. Distribution of schistosome genetic diversity within naturally infected Rattus rattus detected by RAPD markers. Parasitology 113: 511-517.

Bayssade-Dufour Ch 1977. Variation chétotaxique chez les cercaires de Schistosoma mansoni, agent de la bilharziose intestinale en corrêlation avec l'hôte vertébré du parasite. $C R$ Acad Sci 285: 1511-1513.

Bayssade-Dufour Ch 1979a. L'appareil sensoriel des cercaries et la sistématique des trématodes digénêtiques. Mém Mus His natur 113: 1-81.

Bayssade-Dufour Ch 1979b. Variations du systeme sensoriel de la cercarie de Schistosoma mansoni. Intérét éventuel en épidemiologie. Ann Parasit 57: 467-485.

Bonvicino CR, D’Andrea PS, Cerqueira R, Seuánez HN 1996. 
The chromossomes of Nectomys (Rodentia:Cricetidae) with $2 \mathrm{n}=52,2 \mathrm{n}=56$, and interspecific hybrids $(2 \mathrm{n}=54)$. Cytogenet Cell Genet 73: 190-193.

Cassone J, Albaret JL, Jourdane J 1981. L'indice cercarien de Schistosoma mansoni. Données expérimentales et épidémiologiques. Ann Parasit 56: 381-384.

Cassone J, Bayssade-Dufour Ch, Albaret JL, Jourdane J 1978. Variations chétotaxiques des cercaries d'une souche humaine de Schistosoma mansoni par passages sucessifs sur souris. Ann Parasit 53: 387-391.

Combes C, Bayssade-Dufour Ch, Cassone J 1976. Sur l'impregnation et le montage des cercaires pour l'étude chétotaxique. Ann Parasitol 51: 399-400.

Combes C, Léger N, Golvan YJ 1975. Rats et bilharziose en Guadeloupe. Acta Trop 32: 304-308.

D’Andrea PS, Maroja LS, Gentile R, Cerqueira R, Maldonado Jr. A, Rey L 2000. The parasitism of Schistosoma mansoni (Digenea-Trematoda) in a naturally infected population of water rats, Nectomys squamipes (Rodentia:Sigmondontinae) in Brazil. Parasitology 120: 573-582.

Machado-Silva JR, Galvão C, Presgrave OAF, Rey L, Gomes DC 1994. Host-induced morphological changes of Schistosoma mansoni Sambon, 1907 male worms. Mem Inst Oswaldo Cruz 89: 411-414.

Morrison DF 1967. Multivariate Statistical Methods, Mc GrawHill, New York, 318 pp.

Neves RH, Pereira MJS, Oliveira RMF, Gomes DC, MachadoSilva JR 1998. Schistosoma mansoni Sambon, 1907: morphometric differences between adult worms from sympatric rodent and human isolates. Mem Inst Oswaldo Cruz 93: 309312.

Pillay D, Pillay B 1994. Random amplifield polymorphic DNA analysis shows intraspecies variation among Schistosoma mansoni isolates. Med Sci Res 22: 369-371.

Pino LA, Morales G 1990. Análisis discriminante y diferenciación de sexos de Schistosoma mansoni a nivel del estadio cercaria. Rev Ibér Parasitol 50: 233-240.

Pino LA, Morales G, Noya BA, Noya A 1988. La quetotaxia cercariana en la diferenciación de sexos de Schistosoma mansoni. Mem Inst Oswaldo Cruz 83: 367- 374.

Pino LA, Morales G, Matinella L 1997. Quetotaxia cercariana de cepas venezolanas de Schistosoma mansoni. Bol Chileno Parasitol 52: 61-66.

Pinto PM, Brito CFA, Janotti-Passos L, Tendler M, Simpson AJG 1997. Contrasting genomic variability between clones from field isolates and laboratory populations of Schistosoma mansoni. Mem Inst Oswaldo Cruz 92: 409-414.

Quack T, Doenhoff M, Kunz W, Grevelding CG 1998. Schistosoma mansoni: the varying occurrence of repetitive elements in different strains shows sex-specific polymorphisms. Exp Parasitol 89: 222-227.

Rey L 1993. Non-human vertebrate hosts of Schistosoma mansoni and schistosomiasis transmission in Brazil. Res Rev Parasitol 53: 13-25.

Richard J 1971. La chétotaxique des cercaires. Valeur systematique et phylétique. Mém Mus Hist Natur 67: 173.

Rodrigues e Silva R, Machado e Silva JR, Faerstein NF, Lenzi HL, Rey L 1992. Natural infection of wild rodents by Schistosoma mansoni. Parasitological aspects. Mem Inst Oswaldo Cruz 87: 271-276.

Sène MP, Brémond P, Hervé JP 1997. Comparison of human and murine isolates of Schistosoma mansoni from Richard-Toll, Senegal, by isoeletric focusing. J Helminthol 71: 175-181.

Short R, Cartrett ML 1973. Argentophilic "papillae" of Schistosoma mansoni cercariae. J Parasitol 59: 1041-1059.

Smithers SR, Terry RJ 1965. The infection of laboratory hosts with cercariae of Schistosoma mansoni and recovery of the adult worms. Parasitology 55: 695-700.

Vieira LQ, Corrêa-Oliveira R, Katz N 1991. Genomic variability in field populations of Schistosoma mansoni in Brazil as detected with a ribosomal gene probe. Am J Trop Med Hyg 44: 69-78.

Working Comittee for the biological characterization of laboratory animals/GV-SOLAS 1985 . Guidelines for specification of animals and husbandry methods when reporting the results of animal experiments. Lab Animals 19: 106-108. 